\title{
Recommended Standards, Competencies and Best Practices for Infant and Family Centered Developmental Care in the Intensive Care Unit
}

\section{Background}

The emphasis of newborn intensive care focuses on the physical care of the baby. The benefit of developmental care remains secondary, and the parents are often not integrated in the planning, education, decision-making, clinical implementation, and evaluation of their baby's care. However, developmental family centered care is evolving as an essential component of practice for newborns and their families who experience intensive care. Developmental practice currently lacks evidence based standardization and prioritization in order to affect collaborative practice standardization and ultimate outcomes. Consequently, education, communication and policies are inconsistent, and the transition of families to home is wrought with discontinuity.

\section{Objective}

A large body of research supportive of family centered developmental care practices and the resulting positive outcomes for infants and families has emerged. Examination of existing research and practices resulting in interprofessional standards, competencies and best practices is warranted.

\section{Study Design}

An interprofessional committee of experts and parents utilized a systematic review process to evaluate the quality and strength of credible evidence. The concept of infant and family centered developmental care was described, practice components were identified, and evidence based standards and competencies were articulated using a process of consensus approval.

\section{Results}

The Recommended Best Practices and Competencies for Infant and Family Centered Developmental Care (IFCDC) are the result of the consensus process, and are published (https://nicudesign. nd.edu/nicu-care-standards). The components of IFCDC include: systems thinking, positioning and touch, sleep and arousal, skin-to-skin contact, reduction of pain and stress for infants and families, and feeding.

\section{Implications for NIDCAP}

The IFCDC document will assist in the provision of evidence for the on-going practices in newborn contexts within the NIDCAP model. An implementation strategy is required to enable competencies and best practices to be evaluated within each NIDCAP Training Center.

\section{Conclusion}

The successful utilization of IFCDC evidence based standards can integrate the family with the interprofessional team, standardize practice, improve outcome and complement NIDCAP implementation.

\section{References:}

1. Browne JV and the Consensus Committee on Infant Family Centered Developmental Care. Executive Summary: Standards, Competencies and Best Practices for Infant and Family Centered Care in the Intensive Care Unit. Journal Perinatol, 2020 Sep;40(Suppl 1):5-10. doi: 10.1038/s41372-020-0767-1.

2. Consensus Committee on Infant Family Centered Developmental Care. Report of the First Consensus Conference on Standards, Competencies and Best Practices for Infant and Family Centered Care in the Intensive Care Unit. February 2020. https://nicudesign.nd.edu/nicu-carestandards/

3. Consensus Committee on Infant Family Centered Developmental Care. Workshop: Recommended Standards, Competencies and Best Practices for Infant and Family Centered Care in the Intensive Care Unit. Gravens Conference on the Environment of Care for High Risk Newborns, Clearwater Beach, FL. March 4-7, 2020

4. Consensus Committee on Infant Family Centered Developmental Care. Workshop: Recommended Standards, Competencies and Best Practices for Infant and Family Centered Care in the Intensive Care Unit. Gravens Conference on the Environment of Care for High Risk Newborns, Clearwater Beach, FL. March 6-9, 2019

5. Consensus Committee on Infant Family Centered Developmental Care. Workshop: Recommended Standards, Competencies and Best Practices for Infant and Family Centered Care in the Intensive Care Unit. Gravens Conference on the Environment of Care for High Risk Newborns, Clearwater Beach, FL. February 28 - March 3, 2018.

6. Consensus Committee on Infant Family Centered Developmental Care. Workshop: Recommended Standards, Competencies and Best Practices for Infant and Family Centered Care in the Intensive Care Unit. Gravens Conference on the Environment of Care for High Risk Newborns, Clearwater Beach, FL. March 1-4, 2017.

\section{Letter to the Editor}

I can't thank you enough for giving me and Cyprus a place in the Developmental Observer. This article empowers all of us on the island who are working constantly to implement family centre care.

I also need to congratulate you as this issue has so much interesting and useful information on so many levels. It is definitely worth reading!

\section{Pani Pantelides PT}

NIDCAP Professional Consultant Neonatal Physiotherapist and Early Intervention Specialist Nicosia, Cyprus 